\title{
TODO VALLE-INCLÁN EN RED: EL ARCHIVO DIGITAL DEL GIVIUS ${ }^{1}$
}

\section{ALL VALLE-INCLÁN ONLINE: THE GIVIUS DIGITAL ARCHIVE}

\author{
Margarita SANTOS ZAS \\ Universidad de Santiago de Compostela \\ margarita.santos@usc.es \\ Carmen VÍLCHEZ RUIZ \\ Universidad de Santiago de Compostela \\ c.vilchez@usc.es
}

\begin{abstract}
Resumen: Este trabajo presenta el sitio web del Archivo Digital Valle-Inclán/1888-1936 (www.archivodigitalvalleinclan.es). Esto es, el resultado final de un proyecto, inscrito en el panorama de los proyectos digitales de la literatura española de la Edad de Plata, que ofrece un modelo de archivo de autor, concebido no solo como biblioteca digital sino como un potente recurso de investigación. En estas páginas se exponen las características definitorias, acceso, diseño gráfico y estructura de la interfaz web de esta innovadora plataforma digital, así como casos prácticos de consulta e investigación. Este espacio cibernético, consagrado a la obra y figura de Ramón del Valle-Inclán, ofrece en acceso abierto y gratuito el fondo bibliográfico, documental, gráfico e iconográfico del escritor (4.500 documentos / 80.000 imágenes), aportado por el GIVIUS. Su recepción ha sido excelente a tenor de las 50.000 visitas registradas en seis meses. Premio HDH2018 a la mejor herramienta digital.
\end{abstract}

\footnotetext{
${ }^{1}$ Este trabajo se inscribe en el marco del "Programa do Plan Galego IDT" de la Xunta de Galicia para GPC (ED431B 2017/58) y en el Proyecto de Investigación subvencionado por MINECO y Fondos FEDER, "La obra y el legado manuscrito de Valle-Inclán: ediciones y estudios críticos" (FFI2015-70845-R).
} 
Palabras clave: Archivo Digital Valle-Inclán / 1888-1936. Herramienta de investigación. Humanidades Digitales. Literatura española de la Edad de Plata.

Abstract: This paper presents the website of Archivo Digital Valle-Inclán/1888-1936 (www.archivodigitalvalleinclan.es). This is the final result of a project, within the framework of digital projects on The Silver Age of Spanish literature, which offers an author archive model, conceived not only as a digital library, but also as a powerful research tool. Main features, access, graphic design and web interface of this innovative digital platform are presented on these pages, as well as some case studies of hypothetical query and research. This website is devoted to the life and work of Ramón del Valle-Inclán, and it offers an open and free access to bibliographical, documentary, graphical and iconographic files, provided by the GIVIUS (4.500 documents / 80.000 images). Its reception has been excellent according to the 50.000 visits recorded in six months. HDH Best Digital Tool Award 2018.

Key Words: Valle-Inclán Digital Archive / 1888-1936. Research tool. Digital Humanities. Silver Age of Spanish literature.

Hace tan solo un lustro, cuando iniciamos la aventura del Archivo Digital Valle-Inclán / 1888-1936 (ADVI: www.archivodigitalvalleinclan. es), apenas disponíamos de referentes concretos en que apoyarnos. Hoy, como bien señala Dolores Romero (2018: 113), al trazar la Historia digital de la Edad de Plata, en la que también se imbricaría el ADVI, encontramos enlaces de todo tipo, derivados de la "digitalización masiva de contenidos", que se multiplican en bases de datos, archivos o bibliotecas específicas. Pero esta proliferación de plataformas digitales supone también la creación de nuevos recursos y aplicaciones electrónicas, que "no solo sirven para dar información, sino que son instrumentos que generan nuevos procesos de conocimiento en un mundo infinitamente interconectado" (Romero, 2018: 112). Es decir, el incremento de los recursos tecnológicos relacionados con la llamada Edad de Plata - de aplicación a las Humanidades, en general - se han bifurcado para dar origen a una primera línea de 
trabajo, la más transitada y fecunda, que se orienta a preservar y difundir legados culturales, sean artísticos o literarios; y una segunda línea, cuya brújula apunta al propósito de generar métodos de análisis (relacionales, estadísticos, visuales...), aplicables a esos nuevos objetos de estudio, que son los textos digitales, lo cual supone un cambio de paradigma en la investigación literaria.

Pero no perseguimos trazar en este punto un estado de la cuestión de los proyectos realizados en la literatura en español del siglo XX - manuscritos e impresos-, sus objetivos y características ${ }^{2}$, ni dibujar un panorama al detalle de los recursos afines o disímiles de nuestra propia propuesta digital, sino realizar unas cuantas calas en el mapa de la Edad de Plata y destacar, en particular, archivos digitales de autor ${ }^{3}$, territorio al que

\footnotetext{
${ }^{2}$ Los trabajos que citamos ahora, cuyas referencias completas se consignan en la bibliografía, resultan próximos tipológicamente a nuestros intereses, bien sea porque sus autores presentan y analizan archivos digitales de escritores, sobre corpus manuscrito (Pené, Unzurrunzaga y González, 2013; Blixen, Idmhand y Bía, 2017); o sobre corpus impreso (García Ruiz, 2014; Caresani, 2018); bien porque compartimos el mismo marco histórico-cultural con los proyectos que estudian los procesos culturales transnacionales de la primera mitad del siglo XX (Fólica y Roig Sanz, 2017; y Pérez Isasi, 2018); mientras que otros se ciñen a determinados epistolarios (González García, 2014; Arencibia y Domínguez Quintana, 2014) o al género teatral (Martínez Carro y Santa María Fernández, 2019); y, finalmente, nos referimos a aquellos investigadores que se han ocupado en particular de examinar y valorar el estado de digitalización y proyectos de la Edad de Plata (Romero, 2014 y 2018; Calvo Tello, 2017).

${ }^{3}$ En nuestros acercamientos a fuentes que nos brindasen objetos de comparación para valorar en sus justos términos la novedad y aportaciones del ADVI, pues la inmersión en la culminación de tamaña tarea no siempre nos ha dejado ver los árboles, hemos hecho diversas calas en las principales revistas en español de HD (Caracteres, RHD y los dos números monográficos de Artnodes), junto con las actas de los tres congresos de la $\mathrm{HDH}$, que arrojaron un resultado que ofrecemos selectivamente: 1. Entre los proyectos de archivos digitales de autores, se acercan al ADVI por la diversidad de materiales manejados y la presencia de agentes y organismos relacionados: el Archivo Rubén Darío Ordenado y Centralizado (AR.DOC-UNTREF) de la U. Nacional de Tres de Febrero (Buenos Aires) (http://archivoiiac.untref.edu.ar/index.php/rub-n-dar-o [15/06/2019]); y el dedicado a al teatro de Víctor Ruiz de Iriarte, de la U. de Navarra (http://ruiziriarte.com [15/06/2019]). 2. Aunque creados a partir de corpora de manuscritos, pero para el caso, archivos de autor, destacamos el archivo argentino ARCAS, de cuya colección forma parte el Archivo digital de Manuel Puig (http:// arcas.fahce.unlp.edu.ar/arcas/portada/colecciones [15/06/2019]); o el de Delmira Agustini de la Biblioteca Nacional de Uruguay (http://archivodelmira.bibna.gub.uy/omeka/ [15/06/2019]). En esta misma línea cabe mencionar tres archivos anglófonos, dedicados respectivamente a Samuel Beckett (www.beckettarchive.org [15/06/2019]), Jane Austen (https://janeausten.ac.uk/indez. html [15/06/2019]) y Whitman (https://whitman.org [15/06/2019]). Otros proyectos de la Edad de Plata son: "Mnemosine, Biblioteca Digital de La Otra Edad de Plata", liderado por Dolores Romero (UCM), recopilación planificada de datos y metadatos sobre obras raras y olvidadas del periodo comprendido entre 1868-1936 (http://repositorios.fdi.ucm.es/mnemosine/ [15/06/2019]); o
} 
se adscribe el ADVI y, nacido a su amparo, un nuevo proyecto de carácter transnacional en desarrollo ${ }^{4}$.

Dicho esto, nuestro objetivo en estas páginas es adentrarnos en la presentación y caracterización del sitio web del $\mathrm{ADVI}^{5}$, tramo final de un proyecto que acaba de recibir el premio de HDH2018, a la mejor herramienta digital. El Archivo Digital Valle-Inclán/ 1888-1936 es obra del Grupo de Investigación Valle-Inclán de la USC (GIVIUS), dirigido por Margarita Santos Zas, y en él viene trabajando el equipo compostelano desde octubre de 2013. Es el diseño y construcción de este archivo la tarea de mayor envergadura abordada por el GIVIUS, por la inversión de recursos humanos y materiales y el trabajo coordinado de equipos. Su resultado justifica la dilatada trayectoria del Grupo que, por otra parte, ha ido dando cuenta de sus avances en publicaciones ${ }^{6}$ y en congresos ${ }^{7}$ sobre preservación y explotación de archivos de autor y Humanidades Digitales.

Este espacio cibernético, dedicado a la obra y figura de Ramón del Valle-Inclán, comprende un arco de fechas concreto, cuyo terminus

el proyecto BETTE ("Biblioteca Electrónica Textual del Teatro en Español de la Edad de Plata") Universidad Internacional de la Rioja (UNIR), que tiene como finalidad editar en lenguaje de marcado XML-TEI y analizar mediante métodos digitales las piezas dramáticas más relevantes de este periodo (https://github.com/GHEDI/BETTE [15/06/2019]). Para otros proyectos de carácter más general, centrados en la prensa o artistas de la Edad de Plata, véase Romero (2018: 113).

${ }^{4}$ En el seno mismo del GIVIUS y al amparo del modelo del ADVI se ha desarrollado la SilverAgeLab: Translations Database (1914-1940) (silveragelab.net/project/silverage-database/ [15/06/2019]), editada por Rosario Mascato en 2018 (ISSN 2659-9465). Se trata de una base de datos relacional y documental de traducciones de la literatura de la Edad de Plata en cuatro lenguas (inglés, francés, italiano y portugués), diseñada con el fin de examinar la evolución de los mercados culturales a nivel europeo: gustos literarios, propuestas estéticas, jerarquía de los géneros, nóminas anti-canónicas o fluctuaciones del mercado literario, con el propósito de construir una imagen internacional de la literatura española en el período de entreguerras, poniendo el énfasis en la producción de mujeres. Esta base de datos ha sido concebida no solo para dar soporte a las necesidades de información sino con el objetivo de propiciar las capacidades de explotación de los datos recogidos en ella, orientadas tanto a la posibilidad de búsquedas más complejas, como a la obtención de estadísticas, que permitan descubrir patrones de información no evidentes.

${ }^{5}$ El software y la base de datos del Archivo Digital Valle-Inclán / 1888-1936 han sido dados de alta en el registro de la propiedad intelectual con los números de su solicitud (SC 20719 y SC 206 19, respectivamente), que consignamos a la espera de poder disponer del asiento registral.

${ }^{6}$ Sobre el origen y antecedentes del proyecto, véanse Santos Zas et al. (2014); y Vílchez Ruiz (2016: 248-249).

${ }^{7}$ Por lo que se refiere a las intervenciones en congresos de HD, han sido publicadas y, como tales publicaciones, se recogen ya en la bibliografía, excepto la correspondiente al III Congreso de la Sociedad Internacional de Humanidades Digitales Hispánicas (Málaga, 2017), expuesta por Carmen Vílchez, que versó sobre el prototipo de diseño web del ADVI. 
a quo es 1888 - fecha de la primera publicación conocida del escritor, "Babel"- y su terminus ad quem es 1936, año de su fallecimiento y de la aparición de su novela póstuma, El Trueno Dorado, y está disponible para el público desde el 18 diciembre de 2018, con una recepción excelente, si nos atenemos a las casi 50.000 visitas registradas hasta la fecha ${ }^{8}$.

El ADVI ofrece en acceso abierto y gratuito el amplio fondo bibliográfico - 213 ediciones y emisiones de las obras del autor publicadas en vida - , documental — textos de creación editados en revistas y periódicos contemporáneos, artículos, prólogos, entrevistas, conferencias, discursos, cartas, traducciones - gráfico - ilustraciones y motivos ornamentales de sus obras - e iconográfico — caricaturas, retratos, fotografías-, compilado por el GIVIUS durante más de dos décadas en bibliotecas y hemerotecas gallegas, nacionales e internacionales. El 80\% del fondo procede de la prensa de la época y, en su totalidad, está constituido por 4.500 documentos aproximadamente, que traducidos a imágenes digitales superan la cifra de 80.000 .

El archivo continúa incrementándose de forma progresiva con nuevos materiales, pues la labor de exhumación y acopio del GIVIUS es constante. Además, el archivo contiene las transcripciones en formato TXT, realizadas por los integrantes del grupo, de las obras del escritor publicadas en prensa y libro - que suponen en torno a 40.000 páginasademás de 450 TXTs, en números redondos, de entrevistas y conferencias, imprescindibles para posibilitar consultas textuales fiables ${ }^{9}$, aportación

\footnotetext{
${ }^{8}$ El ADVI ha registrado en los siete meses transcurridos desde su puesta en abierto casi 50.000 visitas, exactamente 49.856, con un singular repunte de casi 3.000 visitas a raíz de la concesión del premio HDH2018, que desde aquí queremos agradecer muy vivamente (Fuente: Google Analytics). ${ }^{9}$ El proceso de transcripción consiste en la extracción del TXT de cada una de las ediciones digitalizadas a partir de un software de reconocimiento óptico de caracteres (OCR, Abbyy FineReader 12) que, posteriormente, es revisado por los miembros del GIVIUS para depurar errores de lectura y editar de acuerdo con unos criterios comunes que persiguen la fidelidad al texto original. Tan solo se interviene en aquellos casos en que la lectura imposibilite la devolución de resultados según el criterio lógico de búsqueda. Por ejemplo, en la primera edición de Flor de Santidad (1904) se lee "visidogo". En la transcripción se mantiene la errata y, a continuación, se añade entre asteriscos su corrección: "visidogo *visigodo*". Asimismo, se codifican entre corchetes los números de página y/o fecha de entrega, en el caso de las ediciones periodísticas, para facilitar su localización en la visualización de resultados. Es objetivo primordial del GIVIUS continuar con la transcripción del resto del fondo documental: textos/fragmentos de las obras publicados en prensa, artículos, prólogos, cartas y discursos. Una tarea ingente y laboriosa que se complica con los materiales procedentes de prensa histórica pues el porcentaje de errores del OCR se incrementa notablemente.
} 
esta que consideramos de la mayor utilidad.

Pero este sitio web es mucho más que una biblioteca digital de materiales poco accesibles o vetados hasta hace poco (enero de 2017) por la vigencia de los derechos de autor, ya que constituye también un potente recurso de investigación, gracias al complejo modelo relacional de la base de datos que da soporte a la aplicación web del Archivo Digital Valle-Inclán / 1888-1936 y al Buscador Avanzado implementado ${ }^{10}$, que permite, como veremos al explicar en su lugar los casos prácticos propuestos, obtener en una consulta la historia textual de una obra, información fundamental para realizar una edición crítica; rastrear concordancias en una o varias ediciones u obras mediante la consulta textual cruzada con búsqueda por datos estructurados; o visualizar la red de relaciones tejida por el escritor en el desarrollo de su actividad literaria, social, política y cultural, con los agentes y organismos - editores, autores, ilustradores, destinatarios, periodistas, traductores, instituciones, editoriales, imprentas, etc.- con los que directa o indirectamente se relacionó (más de 2.000). Una de las novedades, inusuales en otros archivos de autor ${ }^{11}$. Esta valiosa información relacional, extraída del modelo de datos diseñado a partir de la labor de investigación previa del equipo académico-investigador, no solo facilita el análisis de la trayectoria y posición del escritor en el campo literario de su tiempo, sino que favorece nuevas aproximaciones al campo artístico de la Edad de Plata ${ }^{12}$. Y ejemplifica, asimismo, la óptima explotación de la información del fondo del GIVIUS, que trasciende la obra literaria del

\footnotetext{
${ }^{10}$ Hay que entender el presente trabajo como parte de un continuum, que enlaza y completa lo expuesto en dos ensayos previos que se han ocupado de la conceptualización del modelo de datos, la herramienta de administración y el desarrollo de la aplicación web del Archivo Digital Valle-Inclán/1888-1936, que firma Vílchez Ruiz (2016) y (2018), respectivamente, de este modo evitamos reiterar en esta tercera entrega lo expuesto en las dos anteriores.

${ }^{11}$ Desde el primer momento en que comenzamos el modelado de datos, advertimos el papel fundamental de agentes y organismos, en nuestro caso relacionados con Valle-Inclán, a la sazón un recurso totalmente inusual, que, sin embargo, hoy es objeto en sí mismo de proyectos digitales, que desarrollan un mapeo de las relaciones entre agentes y organismos en los procesos culturales de la Edad de Plata. Tal es el caso del titulado "Cartografía de la modernidad hispánica. Redes literarias transnacionales y mediadores culturales (España-Latinoamérica, 1908-1939)", que lidera Diana Roig Sanz (Universitat Oberta de Catalunya): https://mapmodern.wordpress.com/cartografiamodernidad/ [15/06/2019]; o el titulado, "Mapa digital de las relaciones literarias ibéricas (18701930)", que dirige Santiago Pérez Isasi (Universidad de Lisboa): http://maplit.letras.ulisboa.pt/es/ inicio/ [15/06/2019].

${ }^{12}$ Para el estudio de las relaciones entre el campo artístico y literario véase Bourdieu (1995: 201209).
} 
escritor.

Por estas razones, el ADVI pretende desempeñar un papel esencial en la recuperación, conservación, análisis y difusión de la figura y obra de Valle-Inclán en la actual sociedad del conocimiento, al mismo tiempo que aspira a ser un modelo de "Archivo Digital de Autor", de referencia tanto para la comunidad académica como para todo aquel interesado en el escritor gallego y su época.

Un proyecto de tal envergadura habría sido imposible sin la financiación de dos Proyectos de Investigación I+D+i (MICINN: FFI2011-24130; y MINECO y Fondos FEDER: FFI2015-70845-R); y de las ayudas concedidas al GIVIUS en convocatorias consecutivas del programa Consolidación e Estructuración de Unidades de Investigación Competitivas de la Xunta de Galicia (GPC2014/039; y ED431B 2017/58, actualmente en vigor).

Los fondos públicos citados nos han permitido contar con un equipo de trabajo interdisciplinar, necesario para el diseño, construcción y desarrollo del Archivo Digital Valle-Inclán / 1888-1936, constituido por dos sub-equipos:

Por una parte, el académico-investigador, dirigido por Margarita Santos Zas, e integrado por los siguientes miembros del GIVIUS: Rosario Mascato Rey, Javier Serrano Alonso, Adriana Abalo Gómez, Francisca Martínez Rodríguez y Carmen E. Vílchez Ruiz, quien, además, ha realizado las labores de gestión del Archivo Digital y la coordinación entre ambos equipos.

Por otra, el científico-técnico, formado por Ángeles Saavedra del Laboratorio de Bases de Datos de la Universidade da Coruña, y Eduardo Rodríguez, Roberto Creo, Andrés Basoa y Vanessa López de la empresa asociada a la UDC Enxenio; y, finalmente, los diseñadores gráficos de la empresa Artenova y la traductora, Karen Barlow.

Por último, el alojamiento web del Archivo Digital ValleInclán /1888-1936 ha sido proporcionado por el Centro Tecnolóxico de Supercomputación de Galicia (CESGA) en virtud de un Convenio Específico de Colaboración suscrito con la USC-Grupo de Investigación Valle-Inclán, que garantiza su mantenimiento y preservación a largo plazo, así como posibilita futuras investigaciones conjuntas de computación avanzada (Big Data, Linked Open Data, Cloud Computing, etc.). 


\section{LA WEB DEL ARCHIVO DIGITAL VALLE-INCLÁN/1888- 1936}

El enunciado de este segundo apartado remite al núcleo del presente trabajo, su desarrollo descriptivo, acompañado de una selectiva muestra de casos prácticos, que quiere poner de relieve la novedad de esta plataforma digital, concebida como un modelo de "archivo de autor".

\section{1. Características generales y acceso}

La web del ADVI, disponible en tres idiomas - español, inglés y gallego ${ }^{13}$ - , está dirigida tanto a investigadores como al público no especializado pero interesado en la figura y obra de Valle-Inclán, que, como hemos podido comprobar ${ }^{14}$, responde a nuestras previsiones y, si bien, las estadísticas arrojan un número más elevado de investigadores, sean o no valleinclanistas, la tipología se ensancha para dar cabida a perfiles que apuntan al valor polivalente del ADVI. Su web, de acceso libre y gratuito, proporciona una navegación intuitiva y permite realizar búsquedas por las diferentes secciones para acceder a la información de forma directa; el diseño de la interfaz es usable (usability) y adaptativo (responsive), haciendo posible la correcta visualización y navegación en cualquier tipo de dispositivo.

Detengámonos en ese acceso a la web, que contempla dos perfiles de usuario con diferentes permisos: el usuario no registrado, que puede acceder a la información de la base de datos, contenida en las secciones del menú principal, y realizar búsquedas; y el usuario registrado mediante un sencillo formulario, quien, a las capacidades anteriores, añade la consulta

\footnotetext{
${ }^{13} \mathrm{~A}$ modo de curiosidad, este archivo ha generado un glosario de mil términos, inglés-español y gallego, que tenemos la intención de editar porque reúne toda la terminología de los menús, discutida por el GIVIUS caso por caso.

${ }^{14}$ Los usuarios proceden fundamentalmente de España, seguida de Estados Unidos, México, Italia, Argentina, Canadá, Colombia, Francia, Portugal, Alemania, Reino Unido y de otros con menor presencia. Por lo que respecta a los usuarios registrados (más de 300), su composición heterogénea evidencia el interés suscitado por el ADVI en diversas disciplinas: al lado de los valleinclanistas, se han registrado investigadores en literatura de diversos periodos, historiadores del arte, gestores o responsables de archivos de escritores, archiveros, bibliotecarios, creadores o empresas de proyectos digitales, profesores de enseñanza secundaria, público general interesado en la obra del escritor, periodistas, etc... Véase complementariamente la nota 8 supra (Fuente: Google Analytics).
} 
en línea de los materiales digitalizados y la oportunidad de descargarlos en formato PDF, así como de acceder al Buscador Avanzado de la aplicación.

\subsection{Diseño gráfico y estructura de la interfaz web}

Desde este punto de vista, procuramos una web limpia y sencilla, en escala de grises, blanco y negro, combinados con rojo granate - señas identitarias del logo del GIVIUS - , que sirve como contraste para destacar cierta información o botones de acción (enviar, buscar, limpiar, etc.). Las fotografías del escritor que ilustran el pie de página y las cabeceras — secciones del menú principal, pestañas informativas o de acceso-, junto a la firma autógrafa - inscrita en el menú central de la página de inicio y en el pie de página-, son una constante que persigue la identificación del sitio web con su objeto: la figura y obra de Ramón del Valle-Inclán.

El diseño de las páginas de la interfaz presenta una estructura estándar, con los elementos organizativos habituales: logo del GIVIUS; menú horizontal superior; cabecera; menú vertical principal del ADVI, ubicado en el lateral izquierdo; contenido y pie. Sin embargo, la página de inicio presenta unas características propias, dada su naturaleza: prescinde de cabecera y muestra un menú principal constituido por una serie de seis retratos fotográficos de Ramón del Valle-Inclán, que dan la bienvenida al usuario (Figura 1): 


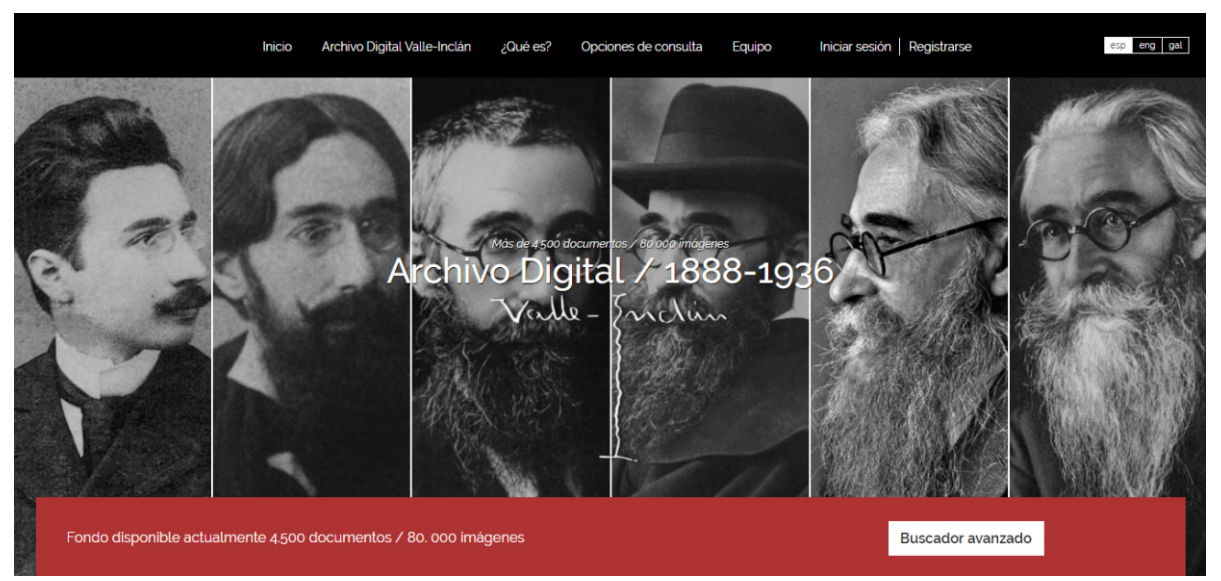

Figura 1. Página principal del Archivo Digital Valle-Inclán / 1888-1936.

Cada fotografía de este recorrido en el tiempo por la imagen del escritor funciona como un hipervínculo que dirige a una sección del menú principal, concretamente, de izquierda a derecha — desde el joven Valle Peña al maduro Valle-Inclán- se suceden: Obras, Documentación, Traducciones Propias, Agentes y Organismos, Iconografía e Ilustraciones. Al pie de las mismas se localiza el Buscador Avanzado; y, por otra parte, nos ha parecido útil incluir una leyenda que informe sobre el número real de documentos e imágenes contenidos en la base de datos en el momento de la consulta (Figura 1).

El contenido restante de la página principal, que puede verse al deslizar (scroll), presenta tres breves secciones informativas: Acceso, ¿Qué es el Archivo Digital Valle-Inclán? y Equipo, que invitan al usuario a ampliar la información, que aquellas muestran extractada, mediante un botón de acción: +info. La última parte del contenido reitera las categorías del menú principal del AVDI.

Del menú horizontal superior que incorpora categorías estándar (acceso, selección de idioma y secciones informativas), cabe señalar la utilidad, aunque en un plano secundario, de Opciones de consulta, porque proporcionan una suerte de manual para el usuario que incluye, asimismo, un dato de interés: las referencias bibliográficas citadas. Por lo que respecta al pie de página, que reitera algunos botones de acceso del menú superior para mejorar la navegabilidad del sitio (vgr.: Iniciar sesión, Registrarse, 
¿Qué es?, Equipo), conviene subrayar la invitación que se hace al usuario desde Colaboraciones externas a aportar documentación inexistente en el Archivo Digital; mientras que una serie de hipervínculos, que se sobreponen a una conocidísima imagen del escritor gallego, remiten a otras secciones informativas —Cómo citar, Enlaces, Aviso legal, Política de cookies, Contacto- - A continuación se sitúan los logos de las instituciones que han intervenido en la ejecución, financiación y hosting del Archivo Digital $\mathrm{y}$, por último, se inscribe el copyright del sitio web.

Las páginas restantes de la interfaz web presentan una cabecera en la que se inscribe el nombre del sitio web y la miga de pan (breadcrumb), una técnica de navegación que permite al usuario conocer en qué lugar de la web se encuentra y qué ruta ha seguido. Las fotografías que se insertan en las cabeceras son elementos identificadores de las diferentes categorías que constituyen los menús superior y vertical. Por ejemplo, en el caso de Obras, la imagen del joven Valle, que la preside, reitera la que figura en la página de inicio. Se observará que las cabeceras de las secciones informativas y de acceso a la web comparten retrato fotográfico - el escritor sentado en un sofá-; mientras que el Buscador Avanzado se identifica con la imagen de Valle-Inclán en sus últimos años, uno de los retratos más famosos del fotógrafo Alfonso, que ha llegado a formar parte del imaginario popular.

El contenido de la página principal de cada sección del menú vertical -Obras, Documentación, Traducciones Propias, Agentes y Organismos, Iconografía e Ilustraciones - presenta dos tipos de menús:

1. Uno, de consulta, que consta de dos niveles: en el primero, un selector permite elegir qué tipo de información se quiere buscar, y, en el segundo, se ofrecen filtros específicos propios de la información contenida en la sección.

2. El otro, de navegación por pestañas, que permite al usuario hacerse una idea rápida y clara de los tipos de material que se ubican en la sección. Así, Obras contiene la creación literaria de Valle-Inclán - prensa y libro- y su traducción a otras lenguas, atendiendo especialmente a la reconstrucción de la historia textual de cada obra; Documentación proporciona información 
de carácter documental relevante para el estudio de la vida y obra del escritor: entrevistas, $\operatorname{cartas}^{15}$, conferencias y discursos; Traducciones Propias recoge las pocas traducciones realizadas por el propio Valle-Inclán; Agentes y Organismos contiene los datos de personajes y organismos con los que Valle-Inclán se relacionó directa o indirectamente durante el ejercicio de su actividad literaria, social, política o cultural; Iconografía recopila la imagen gráfica del escritor clasificada en caricaturas, fotografías y retratos; Ilustraciones expone el material gráfico que ilustra la obra de Valle-Inclán, publicada tanto en librería como en colecciones populares y prensa periódica. Cada una de las pestañas que integran las secciones citadas categoriza un tipo de información que se muestra en forma de listado en las secciones bibliográficas y documentales o en forma de galería en las secciones iconográficas y gráficas. Tanto los ítems del listado como las imágenes de la galería son enlaces que conducen a la ficha del recurso seleccionado.

Por último, el contenido de la página de un recurso correspondiente a una sección del menú principal muestra su imagen en miniatura, con la marca al agua del ADVI-GIVIUS, la información bibliográfica correspondiente y el icono de PDF que da acceso al visor en línea.

A estas secciones del menú principal se suma un potente Buscador Avanzado que permite cruzar consultas por contenido (textual) con búsquedas por datos estructurados. Es decir, permite explotar la información textual de los documentos - mediante TXTs, realizados por el GIVIUS, e incorporados a la base de datos - y filtrar, a su vez, por tipos de publicación, agentes y organismos participantes, e, incluso, imágenes

\footnotetext{
${ }^{15}$ Incorporar las cartas valleinclanianas (367 en este momento) al ADVI fue también objetivo contemplado desde muy pronto. Recordemos el interés que en la historiografía literaria han despertado los epistolarios, objeto de compilaciones, estudios y ediciones, y ahora, como cabía esperar, algunos proyectos han hecho de las cartas su único cometido. Tal es el caso del epistolario galdosiano de la Cátedra Pérez Galdós (http://www.casamuseoperezgaldos.com/epistolariogaldosiano [15/06/2019]); el dedicado a Francisco Ayala, de la Fundación que lleva su nombre (http://www.ffayala.es/epistolario [15/06/2019]) o el proyecto "Epístola" de la Fundación Francisco Giner de los Ríos / Residencia de Estudiantes, que ha desarrollado una herramienta digital "Publicador de Epístola" de momento de uso interno exclusivamente, entre otros.
} 
incluidas en esas publicaciones. Los resultados de las búsquedas pueden exportarse de forma parcial o completa en un documento $\mathrm{CSV}^{16}$.

Es decir, el Buscador Avanzado permite un juego infinito de posibilidades combinatorias, pero grosso modo podemos apuntar las más destacadas que vamos a procurar materializar con ejemplos prácticos que sirvan para mostrar sus potenciales capacidades.

\section{TRES CASOS PRÁCTICOS DE CONSULTA E INVESTIGACIÓN}

Con el propósito de mostrar qué información y qué materiales digitalizados puede ofrecer con todo rigor el Archivo Digital ValleInclán / 1888-1936 como herramienta de investigación, plantearemos seguidamente algunos casos hipotéticos, relativamente comunes para un investigador o estudiante de doctorado, y les proporcionaremos, asimismo, las vías de acceso adecuadas para afrontarlos y resolverlos.

Supongamos, en primer lugar, el caso de una doctoranda, cuya tesis consiste en una edición crítica de una obra dramática del escritor, tan compleja en su génesis como es el caso de Águila de Blasón. Un punto de partida inexcusable para el investigador sería conocer la historia textual de la obra: cuántas ediciones se dieron a la estampa en vida del autor y qué textos se publicaron en prensa para poder reconstruir su prehistoria textual. Esta labor, que hasta hace bien poco resultaba lenta, laboriosa y a menudo incompleta, se facilita y agiliza con el Buscador Avanzado — previo registro-, en cuyo menú habría que realizar la siguiente consulta: buscar publicaciones por tipo, marcar en los resultados serán el filtro ediciones y textos/fragmentosy, a suvez, seleccionar en obra Águila deBlasón(Figura2).

\footnotetext{
${ }^{16}$ Para la descripción detallada de los contenidos, funcionalidades de navegación y consulta de cada sección del menú principal, así como del Buscador Avanzado, véase Vílchez Ruiz (2018).
} 


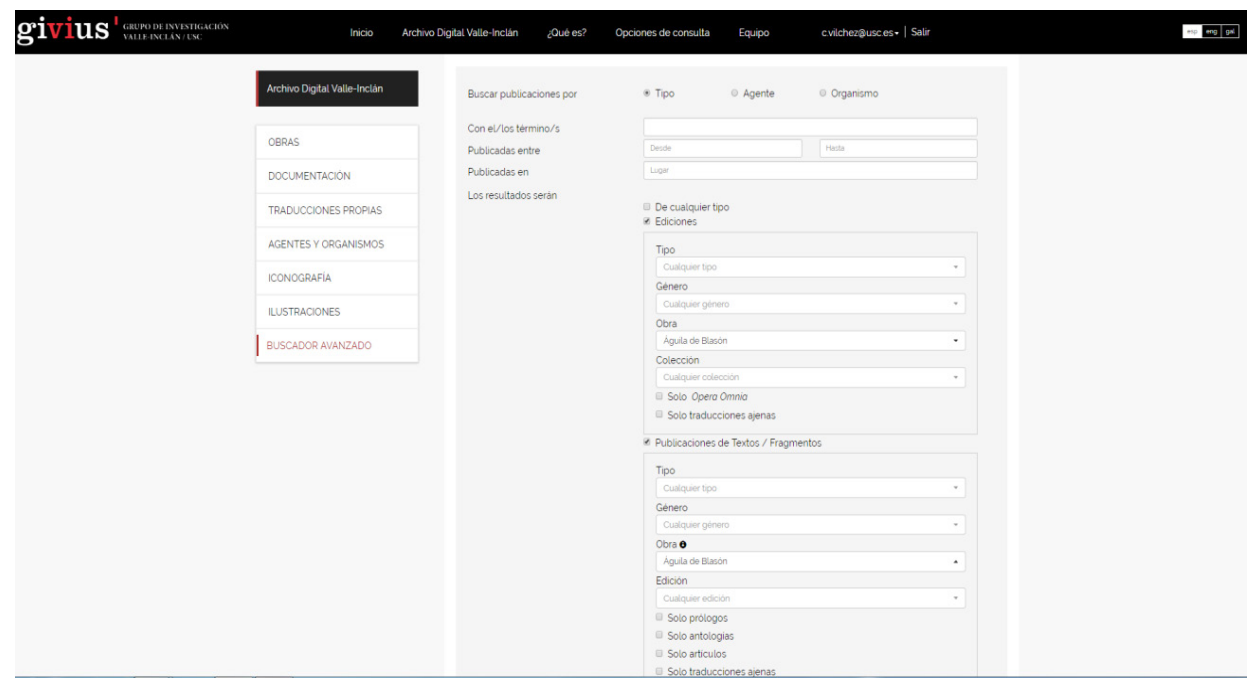

Figura 2. Búsqueda ediciones y publicaciones de textos/fragmentos por obra: Águila de Blasón

El Buscador Avanzado, tras la consulta devuelve la información en dos pestañas: 1. Ediciones: muestra cuatro ediciones de la obra en prensa y libro, junto al PDF de cada recurso, preparado para su visualización en línea y/o su descarga. 2. Publicaciones de textos/fragmentos en la prensa periódica, sistema de publicación muy habitual en el escritor gallego, que editaba fragmentariamente sus obras en periódicos y revistas, bien por entregas con una cadencia de aparición no necesariamente regular, o en textos sueltos, que, posteriormente reelaborados, integraba en una obra. Tal es el caso de Águila de Blasón (1907), que resulta un ejemplo paradigmático de las estrategias de escritura y publicación empleadas por Valle-Inclán, pues nos muestra dieciséis resultados que reúnen los textos publicados en prensa asociados a la obra, así como las varias reproducciones que esos textos tuvieron en periódicos o revistas, aportando también el PDF respectivo (véanse Figuras 3 y 4). Con estos materiales, la doctoranda dispondría de una información rigurosa para reconstruir la historia textual de esta Comedia Bárbara y una base sólida para afrontar su edición crítica. 

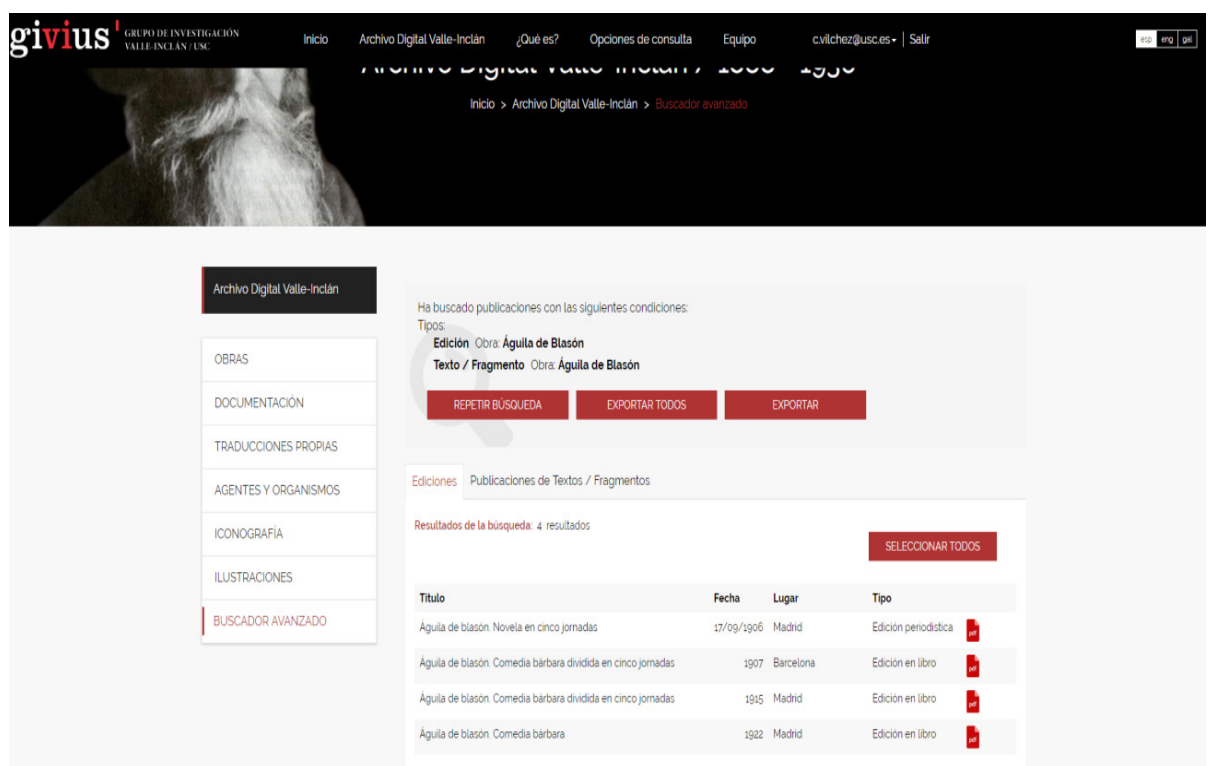

Figura 3. Resultados pestaña ediciones de Águila de Blasón.

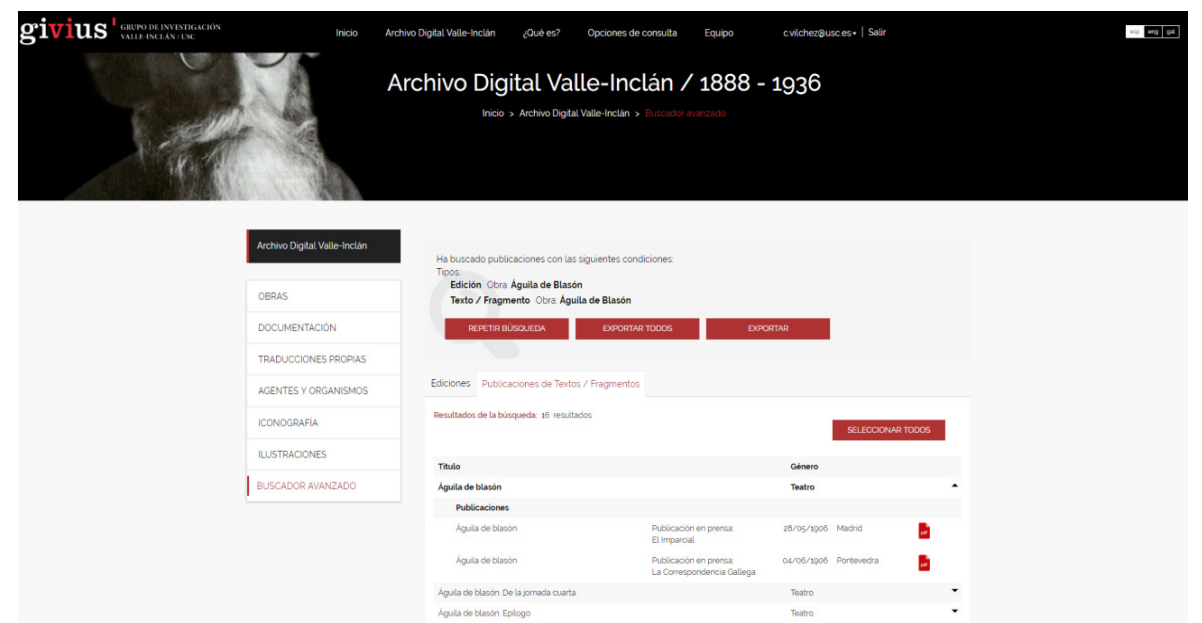

Figura 4. Resultados pestaña publicaciones de textos/fragmentos de Águila de Blasón. 
Estos resultados, además, podrían exportarse en un documento CSV, lo que permitiría también trabajar desconectado (off-line).

De manera complementaria, la doctoranda podría averiguar las opiniones de Valle-Inclán sobre esta primera Comedia bárbara en entrevistas, cartas o conferencias, así como rastrear información sobre el estreno de la obra. Una búsqueda textual con el/los término/s, en este caso, cadena literal, "águila de blasón", devolvería aquellos materiales en los que figurase el criterio de búsqueda.

Un segundo caso hipotético, contemplaría la anotación de una edición crítica de Divinas Palabras y para ello necesita ejemplos de intratextualidad sobre la expresión, por ejemplo, "Noche de luceros". Este cometido que supondría una relectura de las obras del escritor en "busca y captura" de la recurrencia de la expresión citada, se simplifica en el ADVI al introducir en el campo con el/los término/s la cadena de texto entre comillas, "Noche de luceros", y acto seguido comprobar los resultados, que remiten, por su parte, a pasajes de Los Cuernos de Don Friolera y Viva mi dueño, en los que se halla esa misma expresión. Debemos destacar aquí la visualización de resultados de la búsqueda textual, pues permite leer el criterio de búsqueda contextualizado y marcado en negrita, con indicación del número de página del documento en el que se halla. Incluso, en el caso de ediciones periodísticas se indica además fecha y número de la entrega, para facilitar su ubicación. Esta funcionalidad facilita el proceso de cita en el documento de trabajo del investigador, ya que solamente tiene que copiar y pegar del documento CSV exportado (véase Figura 5). 


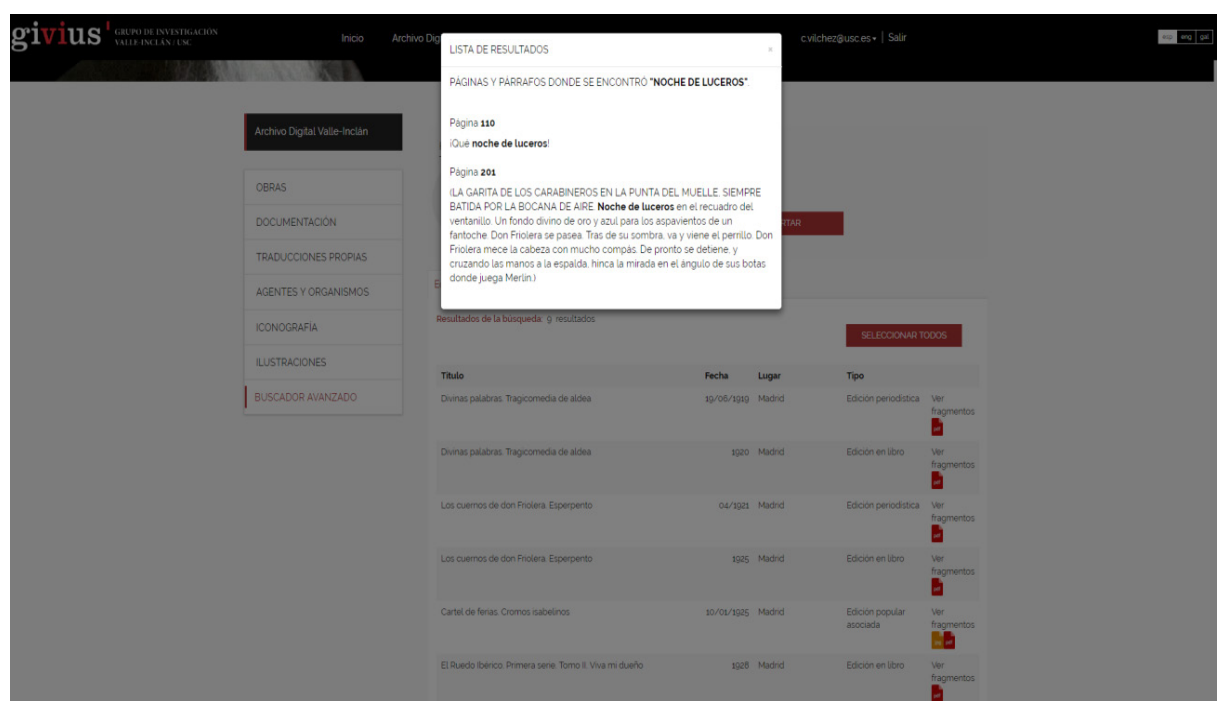

Figura 5. Visualización resultados búsqueda textual en Los Cuernos de Don Friolera (1925).

Este mismo tipo de consulta cabría aplicarse, por ejemplo, a estudios lingüísticos sobre el uso de galleguismos, tan frecuentes en la obra del escritor - vgr. boira, lóstrego- y calcos en español de términos y perífrasis gallegas — vgr. "cueva", utilizado en este caso como sinónimo de cova con el significado de "tumba"; ter + participio: tengo entrevisto-. Mecanismo extrapolable al lenguaje esperpéntico, al uso de galicismos, latinismos, americanismos, gitanismos, términos de jerga, argot y un larguísimo muestrario del que hace gala la obra de Valle-Inclán, cuya riqueza lingüística es una de sus primordiales señas de identidad.

Por último, planteamos la hipótesis — entre otras posibles-, de un supuesto especialista en la figura y obra de Salvador Bartolozzi, interesado en los trabajos de ilustración que realizó para numerosas publicaciones periódicas y colecciones populares contemporáneas al escritor. Valiéndose del Buscador Avanzado, podría obtener las que el artista madrileño realizó para ilustrar textos de Valle-Inclán. La vía adecuada es buscar publicaciones por tipo y filtrar por el agente participante "Bartolozzi” (véase Figura 6): 

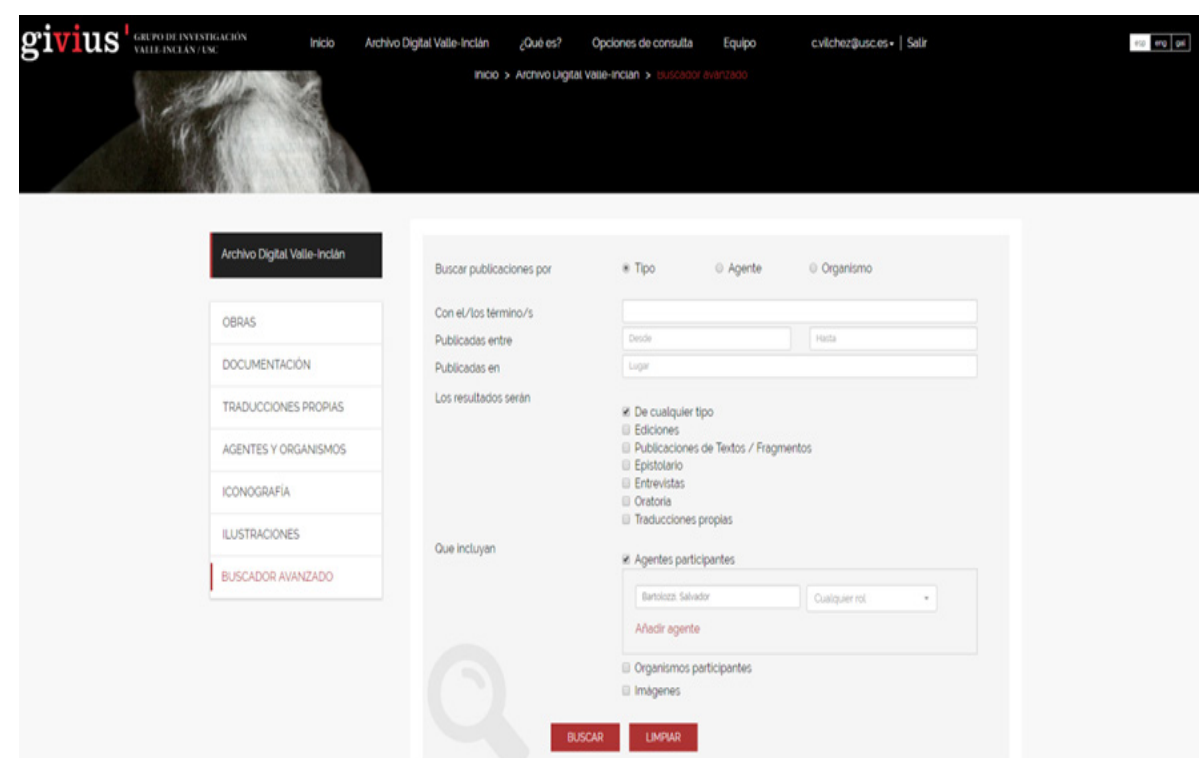

Figura 6. Búsqueda por agente participante "Bartolozzi".

El resultado de la búsqueda devuelve en dos pestañas (1. Ediciones; 2. Publicaciones de textos/fragmentos) las publicaciones de Valle-Inclán ilustradas por Bartolozzi. La primera, muestra una edición popular asociada, que vio la luz en la colección La Novela Semanal. La segunda, proporciona un poema del escritor gallego, editado en la revista La Esfera. En ambos casos, junto al icono de PDF aparece también el del recurso JPG. Para visualizar este último, debemos clicar sobre el icono que conduce a la ficha de la publicación, que contempla una sección para las ilustraciones contenidas (Figuras 7 y 8): 

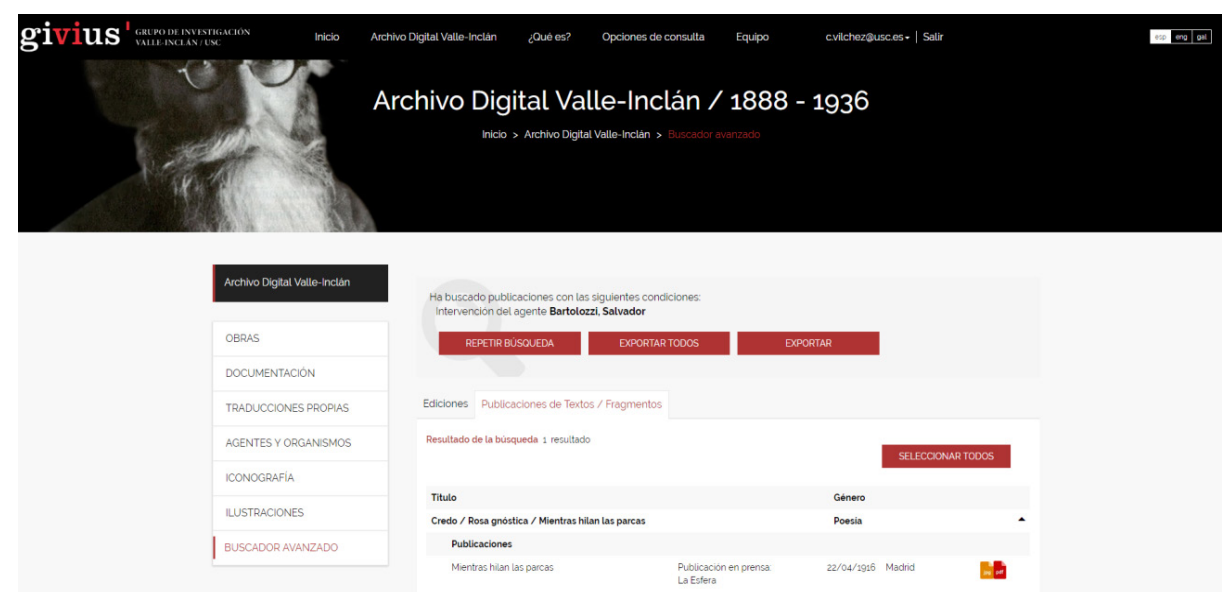

Figura 7. Resultado búsqueda por agente "Bartolozzi" en pestaña publicaciones de textos/fragmentos.
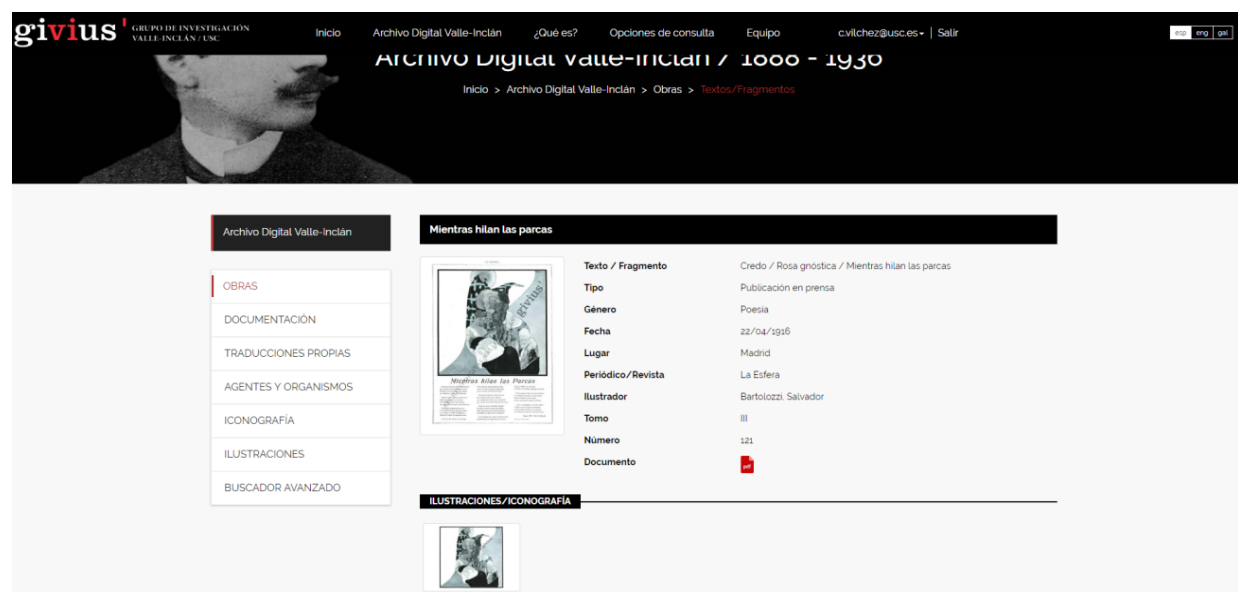

Figura 8. Ficha de publicación del poema ilustrado por Bartolozzi.

Este tipo de consulta también podría realizarse directamente acudiendo a la sección de Agentes y Organismos del menú principal, donde obtendríamos, en primer lugar, las ilustraciones de Bartolozzi (Figura 9). 

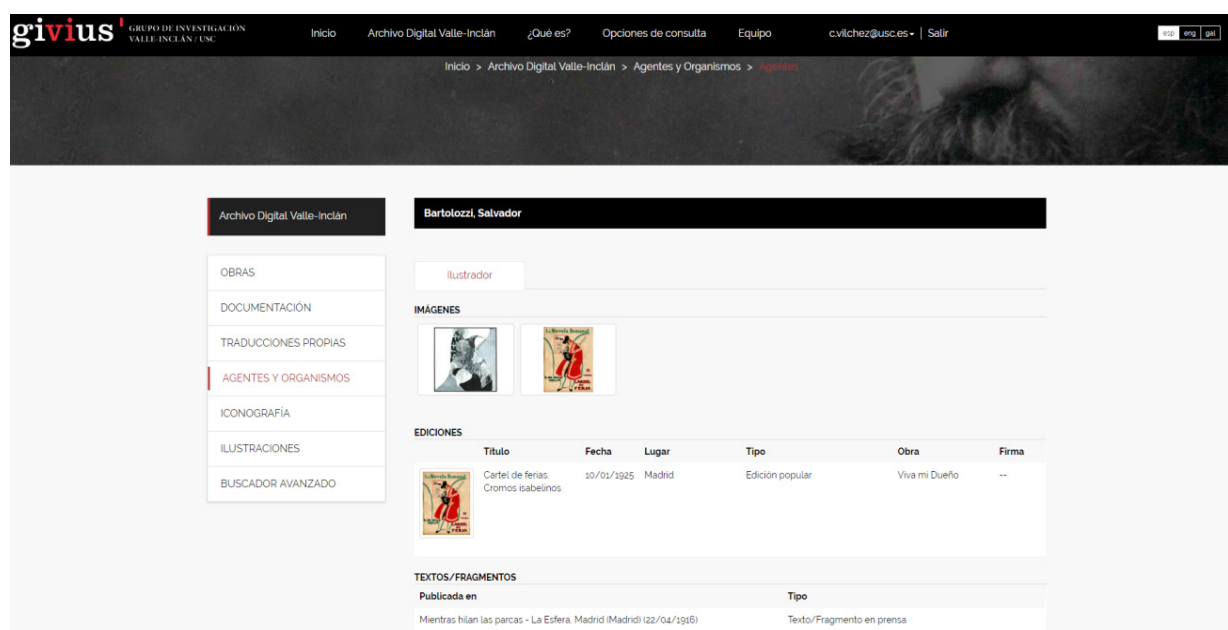

Figura 9. Resultado búsqueda por agente "Bartolozzi” en la sección Agentes y Organismos.

Tras esta sintética muestra de hipotéticos casos prácticos, se infieren infinitas posibilidades de consulta y explotación de la información contenida en el Archivo Digital Valle-Inclán /1888-1936. Pero si estos ejemplos evidencian que el ADVI es un potente y versátil instrumento de consulta, investigación y difusión de la vida y obra de uno de los principales renovadores de la literatura española del siglo $\mathrm{XX}$, es preciso añadir que las capacidades descritas no agotan su potencial. Y volvemos al principio de esta exposición para cerrar el círculo.

El ADVI ha dado al GIVIUS carta de ciudadanía en el ámbito de las Humanidades Digitales —el reciente Premio HDH2018, antes enunciado, lo respalda - porque sus características definitorias lo convierten en una innovadora plataforma digital que, en primera instancia, representa, como acabamos de ver, lo que Dolores Romero (2018: 110-117) define, al referirse a las aportaciones de los proyectos digitales en general y, singularmente, en el campo de la Edad de Plata, como una herramienta que permite ver más y mejor, aplicable en nuestro caso a la producción y trayectoria literarias de Valle-Inclán.

Pero más allá de preservar, visibilizar y difundir un legado cultural - un valioso patrimonio-, por tanto, más allá de su función de informar, línea de trabajo a la que en principio se adhiere el ADVI, este archivo es también un instrumento que genera nuevos procesos de conocimiento. 
Quiere decirse que la conversión de todos los materiales valleinclanianos en objetos digitales supone un ingente corpus, susceptible de la aplicación de métodos de análisis y herramientas propias de las HD (vgr. topic modeling, minería textual - text mining - o estilometría) con fines distintos: desde llevar a cabo estudios de redes que conforman la producción editorial de Valle-Inclán, hasta descubrir patrones ocultos semánticos, estilísticos, organizativos... Quiere decirse que el ADV potencialmente permite también ver de forma diferente, en expresión nuevamente de Dolores Romero (2018: 114).

Y aquí reside su principal potencial en el campo de las HD. Bien es verdad que apenas hemos empezado a asomarnos a estas posibilidades analíticas, que en el GIVIUS inaugura un ensayo sobre la poesía de Valle-Inclán, firmado por Rosario Mascato (2019). Se trata de la primera aproximación al corpus digital valleinclaniano más allá de su dimensión informativa, que aporta, por una parte, una serie de reflexiones teóricas preliminares sobre potenciales tratamientos contracanónicos de dicho corpus; y en el terreno concreto de la praxis analítica, trata de testar algunas técnicas o métodos de análisis estadísticos y probabilísticos (text-mining, topic modeling), aplicados al estudio de los recursos léxicos del escritor, ceñido para la ocasión a uno de los tres poemarios valleinclanianos, $L a$ Pipa de Kif (1919), aunque con el propósito explícito de proyectar su rentabilidad sobre un corpus mayor - solo así adquiere sentido-, que precisamente proporcionaría el ADVI.

Cabría añadir a lo expuesto un apunte final, que ni somos las primeras ni las únicas en manifestar, a saber: por sugestivo que resulte indagar en estos ámbitos, prácticamente inexplorados, nos inquieta la conversión de la herramienta y la metodología digital en un fin en sí mismo, que arrastra como secuela muchas veces la falta de rigor analítico, tendencia que hemos visto repetirse como algo cada vez más habitual en recientes congresos. Por el contrario, nuestra posición en este punto es clara: consideramos fundamental que los nuevos parámetros teóricometodológicos se asienten sobre los conocimientos adquiridos en nuestro propio ámbito humanístico y que esto sea un valor y no un demérito. Es necesaria la formación, el conocimiento de los mecanismos y técnicas de análisis y procedimientos para evitar el desdén sin fundamento, para saber seleccionar ad hoc, para poder posteriormente interpretar resultados $\mathrm{y}$, sobre todo, para decidir con conocimiento de causa, si estos instrumentos son ancilares de otras finalidades o una finalidad en sí mismos. 


\section{REFERENCIAS BIBLIOGRÁFICAS}

ARENCIBIA SANTANA, Y. y DOMÍNGUEZ QUINTANA, R. (2014). "Hipertexto de Pérez Galdós. El epistolario (HPGE)". En Visibilidad y divulgación de la investigación desde las Humanidades digitales. Experiencias y proyectos, Álvaro Baraibar (ed.), 233-242. Pamplona: Servicio de Publicaciones de la Universidad de Navarra. BOURDIEU, P. (1995). Las reglas del arte. Génesis y estructura del campo literario. Barcelona: Anagrama.

BLIXEN, C.; IDMHAND, F. y BÍA, A. (2017). “Omeka y la edición digital de los cuadernos de Delmira Agustini”. En Libro de resúmenes del III Congreso de la Sociedad Internacional HDH: Sociedades, Políticas, Saberes, Nuria Rodríguez Ortega (ed.), 216-217. Málaga, 18-20 de octubre.

CALVO TELlO, J. (2017). "Estado de la digitalización de la Edad de Plata: un análisis cuantitativo". Revista de Humanidades Digitales 1, 76-95. Disponible en línea: http://revistas.uned.es/index.php/ RHD/article/view/17089 [15/06/2019].

CARESANI, R. J. (2018). "Humanidades digitales desde el Sur: el Archivo Rubén Darío como prototipo". En Primeras Jornadas de la Red de Archivos Literarios Latinoamericanos, Montevideo, 4-5 de septiembre.

GARCÍA RUIZ, V. (2014). "El caso del teatro español de posguerra: Víctor Ruiz Iriarte editado en la red”. En Visibilidad y divulgación de la investigación desde las Humanidades digitales. Experiencias y proyectos, Álvaro Baraibar (ed.), 307-322. Pamplona: Servicio de Publicaciones de la Universidad de Navarra. Disponible en línea: http://dadun.unav.edu/handle/10171/35732 [15/06/2019].

GONZÁLEZ GARCÍA, J. M. (2014). "El proyecto Epístola: edición digital de los epistolarios de la Edad de Plata". Janus, Anexo 1, 197-208.

FÓLICA, L. y ROIG SANZ, D. (2017). "Cartografía de la modernidad hispánica: el uso de Nodegoat en la construcción de un entorno digital de investigación". En Libro de resúmenes del III Congreso de la Sociedad Internacional HDH: Sociedades, Politicas, Saberes, Nuria Rodríguez Ortega (ed.), 307-309. Málaga, 18-20 de octubre. 
MARTÍNEZ CARRO, E. y SANTA MARÍA FERNÁNDEZ, T. (2019). "Biblioteca Electrónica Textual del teatro español (1868-1936) e investigación con grafos". Revista de Humanidades Digitales 3, 23-45. Disponible en línea: http://revistas.uned.es/index.php/RHD/ article/view/23144/19092 [15/06/2019].

MASCATO REY, R. (2019). "El corpus digital valleinclaniano: nuevas aportaciones y reflexiones sobre potenciales análisis con La Pipa de Kif al fondo". Anales de Literatura Española Contemporánea 44.3, 21-56.

PENÉ, M.; UNZURRUNZAGA, C. y GONZÁLEZ, C. (2013). “Difusión y preservación digital de los papeles de autores destacados. Proyecto ARCAS, un ejemplo de articulación entre grupos de investigación y biblioteca". En VI Jornadas Internacionales de Filología y Lingüística y Primeras de Crítica Genética "Las lenguas del archivo". La Plata, 7-9 de agosto.

PÉREZ ISASI, S. (2018). "Hacia un mapa digital de las relaciones literarias ibéricas (1870-1930): algunas reflexiones teóricas y metodológicas". Artnodes 22, 93-101. Disponible en línea: http:// dx.doi.org/10.7238/a.v0i22.3200 [15/06/2019].

ROMERO LÓPEZ, D. (2014). "Hacia la Smartlibrary: Mnemosine, una biblioteca digital de textos literarios raros y olvidados de la Edad de Plata (1868-1936). Fase I". Janus, Anexo 1, 411-422.

(2018). "La Edad de Plata en la tarima digital. Hacia la transdisciplinariedad y la cultura smart". Artnodes 22, 110-117. Disponible en línea: http://dx.doi.org/10.7238/a.v0i22.3215 [15/06/2019].

SANTOS ZAS, M.; MARTÍNEZ RODRÍGUEZ, F. y MASCATO REY, R. (2014). "La creación y gestión del archivo digital valleinclaniano: corpus manuscrito e impreso". Janus, Anexo 1, 435-457.

VÍLCHEZ RUIZ, C. E. (2016). "El Archivo Digital Valle-Inclán: corpus impreso". Signa: Revista de la Asociación Española de Semiótica 25, 247-270. Disponible en línea: http://revistas.uned.es/index. php/signa/article/view/16956 [30/05/2019].

(2018). “ElArchivo Digital Valle-Inclán: aplicación web". En Ciencias Sociales y Humanidades Digitales Aplicadas. Casos de estudio y perspectivas críticas, Esteban Romero Frías y Lidia Bocanegra Barbecho (eds.), 361-385. Granada / Nueva York: Universidad de 
Granada / Downhill Publishing. Disponible en línea: https://doi. org/10.5281/zenodo. 1469337 [30/05/2019].

Recibido el 13 de marzo de 2020.

Aceptado el 29 de abril de 2020. 